\title{
Sobre demos, cracias y gogias. Reflexiones sobre las democracias
}

\section{On Demos, Kratos and Gogies. Reflection on Democracies}

\author{
Ramón A. Feenstra ${ }^{1}$ \\ Universitat Jaume I de Castelló (España) \\ Yanina Welp ${ }^{2}$ \\ University of Zurich (Suiza)
}

Recibido: 10-01-19

Aprobado: 30-03-19

\section{Resumen}

El problema se ha nombrado de muchas maneras: incapacidad de proveer políticas acertadas, corrupción, desencanto o abstención electoral, entre otros indicadores de la crisis de legitimidad que atraviesan al sistema. En la búsqueda de soluciones, se discute la viabilidad de mecanismos alternativos o complementarios a los representativos: ¿Es el referendo un buen instrumento para incluir a la ciudadanía en la toma de decisiones? ¿Pueden los procesos deliberativos contrarrestar los efectos de las fake news? ¿Debería el gobierno de los expertos reemplazar a los "incompetentes políticos"? o ¿Debería promoverse el gobierno de "los comunes", seleccionados por sorteo? Aquí discutimos determinados modelos de democracia disponibles -representativa, participativa, deliberativa, aleatoria y monitorizada-para proponer una "ecología de la participación". En otras palabras, sugerimos entender los mecanismos de

\footnotetext{
${ }^{1}$ (feenstra@uji.es). Miembro del proyecto de investigador "El potencial de las éticas aplicadas en las herramientas de participación del Gobierno Abierto y de la sociedad civil" (UJI-A2016-04), es profesor del Departamento de Filosofía y Sociología de la Universitat Jaume I de Castellón. Es autor de varios libros, el último ha sido Kidnapped democracy (Rowman \& Littlefield, 2019) y co-autor, de La reconfiguración de la democracia. El laboratorio político español (Comares, 2016). Desde el 2011 es editor de Recerca. Revista de Pensament i Anàlisi.

2 (yanina.welp@zda.uzh.ch). Doctora en Ciencias Políticas y Sociales en la Universidad Pompeu Fabra (España). Se especializa en el estudio de la participación política, tema sobre el que ha publicado libros, artículos y capítulos de libro. Su último monográfico es Todo lo que necesitás saber sobre las democracias del siglo XXI (Paidós 2018).
} 
ejercicio del poder, en un sistema determinado, como estructuras de incentivos socio-políticos que promueven la formación de consensos o la polarización, el control o la delegación, la ampliación de la agenda pública o su restricción, la demagogia o el debate informado.

Palabras-clave: democracia, participación, ciudadanía, modelos de democracia.

\begin{abstract}
The problem has been described in many ways: inability to provide accurate politics, corruption, disillusionment or electoral abstention among other indicators of the crisis faced by the political system. The search for solutions spawns a debate on the viability and fairness of mechanisms that offer an alternative to or a complement of representative systems: Are referendums a good mechanism for engaging citizens in decision making? Can deliberative processes offset the effects of the "fake news"? Should a government of experts replace "incompetent politicians"? Should governments be in charge of ordinary citizens selected by sortition? Here, we discuss the democratic models available - representative, participative, deliberative, random and monitorised - to propose an "ecology of participation". In other words, we suggest an understanding of the mechanisms for exercising power in a given system as structures of political incentives that foster the formation of consensus or polarisation, control or delegation, an expanded or a restricted public agenda, demagogy or informed debate.
\end{abstract}

Key-words: democracy, participation, citizenship, models of democracy.

\title{
Introducción
}

Para la teoría política contemporánea, la democracia se sustenta sobre la base de que el pueblo constituye la fuente legítima y originaria del poder político. En la práctica, la democracia se ha materializado en diversas instituciones con legitimidad de origen (por ejemplo, gobiernos electos directamente por el pueblo) y derivada (como es el caso del Poder Judicial, nombrado en procedimientos que no implican el voto popular). Además, la realización del ideal democrático presenta diversas graduaciones en cuanto a implicación y posibilidades que se ofrecen a la ciudadanía para formar parte de la toma de decisiones colectivas (Dahlberg y Siapera, 2007; Whitehead, 2011; Welp y Ordóñez, 2017). 
En términos generales, la representación política y las diferentes estructuras sobre las que se sustenta forman el andamiaje sobre el que se materializa el ideal de la soberanía popular. Aunque el sistema nunca ha sido ni estático (inmutable a lo largo del tiempo) ni homogéneo (idéntico en el espacio que agrupa regímenes democráticos), en la actualidad se evidencian síntomas de una crisis extendida. Las instituciones definitorias de una democracia representativa - partidos políticos, parlamentos y elecciones periódicas- son percibidas por la ciudadanía con desafección (Mair, 2015). La tensión -y la distancia creciente- entre las expectativas (y esperanzas) que se dan entre el ideal democrático y su realización puede explicar algunos de los motivos por los que crece el desencanto. Esto no es simplemente una disquisición teórica, ya que tiene consecuencias directas sobre la legitimidad del sistema y también sobre la misma definición de los asuntos públicos (Tormey, 2015; Eberhardt, 2015). Es obvio que una crisis económica tiene dimensiones que exceden lo simbólico, sin embargo, la percepción de la justicia del accionar del gobierno y la eficiencia del sistema político afectarán no sólo su interpretación (¿podría el gobierno haberla evitado?) sino también los mecanismos que se activan frente a ella (protesta, generación de redes de solidaridad, creación de nuevos partidos, abstención electoral, etc.).

Tres aspectos son claves determinando incentivos políticos a la participación de la ciudadanía: 1) cómo se eligen las autoridades, 2) cómo se toman las decisiones y 3) cómo se controlan (las autoridades y la implementación de políticas). Con foco en estos tres aspectos, proponemos analizar la estructura de incentivos que distintos modelos democráticos podrían ofrecer. Estos son: la democracia representativa y las que se han propuesto para complementarla o reemplazarla: la participativa (Santos y Avritzer, 2004), la deliberativa (Dryzek, 2002), la aleatoria (Van Reybrouck, 2016) y la monitorizada (Keane, 2009; Alonso et al 2011, Feenstra, 2013). Optamos por trabajar con la noción de modelo como estrategia analítica de reconocida utilidad en las Ciencias Sociales, no con la idea de que estos puedan identificarse con pureza. Anticipamos también que nuestra reflexión apunta a discutir desde la teoría pero con una intención práctica (y pragmática) los mecanismos que podrían contribuir a fortalecer las democracias existentes y, en particular, reducir los incentivos políticos a discursos demagógicos.

A continuación presentamos el marco conceptual. Luego analizamos brevemente los distintos modelos de democracia mencionados arriba $\mathrm{y}$, finalmente, argumentamos en favor no de un modelo en particular - de hecho discutiremos que las opciones alternativas a la representación sean realmente modelos- sino de la combinación de mecanismos que permitan generar mayores contrapesos y mecanismos de apertura (profundizando en la propuesta de "ecologías participativas"). 


\section{Marco conceptual: sobre las formas de organización del gobierno}

En el campo de las ciencias sociales, la delimitación teórica de la noción de "modelo" comparte las dificultades que acompañan a la definición de tipos ideales o taxonomías, en la medida en que responden a unos constructos mentales capaces de identificar algo que no se observa de forma pura. Esto es así porque su funcionalidad es explicativa y heurística (Weber, 1978; Giddens, 2013). Un modelo busca comprender la complejidad simplificándola a partir de la selección de sus elementos indispensables. La investigación empírica, luego, tendrá que hacer operativos estos conceptos para poder hacer observaciones. En el caso de los modelos de democracia, a los retos que los procesos de abstracción generan se añade la tensión siempre presente entre lo descriptivo y lo normativo, es decir entre lo que la democracia es y lo que debería ser (según la posición de quien enuncie la propuesta).

Para Held, el "modelo de democracia" devela una "construcción teórica diseñada para revelar y explicar los elementos clave de una forma democrática y su estructura subyacente de relaciones" (1991: 23). Es decir, un modelo recoge los pilares fundamentales sobre los que una propuesta democrática define elementos centrales tales como el significado de la participación (y sus límites), el papel de la ciudadanía y de los gobernantes y la distribución de responsabilidades entre estos. De esta manera, un modelo de democracia especifica y detalla aspectos como los mecanismos de selección de gobernantes, los procesos de tomas de decisiones y los sistemas de rendición de cuentas. Y tal y como veremos más adelante, la concreción de estos elementos permite más que catalogar modelos de democracia diversos añadirle adjetivos. Esto es, según exija mayores o menores niveles de involucramiento de la ciudadanía en los asuntos públicos (de las propuestas minimalistas a las participacionistas) o según los heterogéneos mecanismos de participación que definan (representación electoral, sorteo, monitorización, participación, deliberación, etc.) la democracia (representativa) adquirirá otros atributos que idealmente podrían reforzarla. Sin embargo, el uso instrumental e interesado de estos mecanismos podría más bien reforzar su crisis. Esto ocurriría si los referendos son manipulados para reforzar el poder del presidente frente a sus adversarios o si los procesos deliberativos son poco más que una estrategia gatopardista para insinuar cambios radicales (en las formas de hacer) sin cambiar nada realmente.

La definición de modelos o tipos es un procedimiento clásico en la reflexión política. Para Aristóteles, un régimen político es una ordenación de las diversas magistraturas de la ciudad y especialmente de la que tiene el poder soberano. Así, en las repúblicas es soberano el pueblo, y, por el contrario, en las oligarquías la minoría (Política, Libro III). Es muy conocida su división en tres formas de gobierno virtuosas y sus desviaciones. Los primeros se distinguen por 
velar por el interés común y los segundos por atender a sus propios intereses. Se trata de la monarquía (gobierno de uno), la aristocracia (gobierno de pocos) y la república (gobierno de muchos). Sus desviaciones son la tiranía, la oligarquía y la democracia. Así pues, Aristóteles presenta una clasificación atendiendo a los criterios de cantidad -distribución de poder- y de calidad -objetivo de la comunidad- y señala que "(...) hay oligarquía cuando los que tienen la riqueza son dueños y soberanos del régimen; y, por el contrario, democracia cuando son soberanos los que no poseen gran cantidad de bienes, sino que son pobres" (Política, Libro III, 1279b, 446).

Aristóteles recurre al concepto de demagogia, un término poco empleado en las ciencias humanas y sociales a la hora de interpretar o analizar la democracia. La demagogia es, según este autor, la estrategia desarrollada por el gobierno oligárquico para atraerse a la multitud y ser elegido por ella. Más concretamente Aristóteles señala que “(...) sucede lo mismo en todas las oligarquías donde los magistrados no son elegidos por la misma clase que desempeña las magistraturas, sino que las magistraturas salen de los que tienen grandes rentas o de los círculos políticos pero los eligen los hoplitas o el pueblo". (Política, Libro V, 1305b, 1018).

La idea de demagogia como desvirtuación del sistema democrático se observa en su acepción contemporánea, como muestran las dos definiciones que ofrece la Real Academia Española, que la define como: 1) una "práctica política consistente en ganarse con halagos el favor popular", y 2) una "degeneración de la democracia, consistente en que los políticos, mediante concesiones y halagos a los sentimientos elementales de los ciudadanos, tratan de conseguir o mantener el poder". Dos son, por tanto, las connotaciones claves que podemos extraer de este concepto: su comprensión como estrategia para mantenerse (o conseguir) el poder político así como la asociación con una desvirtuación de la democracia (y los principios que la acompañan).

Ambos significados de demagogia son de utilidad para el propósito de nuestro análisis ya que los modelos contemporáneos de democracia definen (como ya hemos indicado) diversos mecanismos de selección de gobernantes, procesos de toma de decisiones y sistemas de rendición de cuentas. Con ello se proponen heterogéneos incentivos políticos para la participación, el acceso a información, la formación cívica, la movilización o la deliberación de la ciudadanía; y según las estructuras que desarrollen pueden contribuir a fomentar los consensos o la polarización, el control o la delegación, la ampliación de la agenda pública o su restricción.

Se ha extendido la noción de "democracia representativa" (Verba y Nie, 1972), pero los movimientos de protesta social han puesto en duda que realmente exista: las consignas son elocuentes: "Le llaman democracia pero no lo es", 


\begin{abstract}
"somos el 99\%", "democratizar la democracia"3. Mientras más recientemente han proliferado los estudios que identifican señales de erosión. Aristóteles ya advertía de esta posible tensión frente a la que, en el escenario contemporáneo, han proliferado los modelos en disputa. Cabe reflexionar entonces sobre los incentivos positivos y negativos que podrían generar y sobre su viabilidad. En este trabajo defendemos que mayor fiscalización y participación en manos de la ciudadanía permiten reducir el campo para la demagogia. Las claves, distribuir el poder, los mecanismos de control, la capacidad de incidencia ciudadana y sus competencias para ejercerla.
\end{abstract}

\title{
Los modelos de democracia contemporáneos
}

Son numerosas las propuestas de revitalización de la democracia existentes. Aquí nos circunscribiremos a aquellas que han generado un amplio debate en la teoría y la ciencia política contemporánea y que han dado lugar a iniciativas concretas, de mayor o menor calado. Introducimos cinco: democracia representativa, democracia participativa, democracia deliberativa, democracia aleatoria y democracia monitorizada. No se trata -no sería posiblede profundizar en todos sus aspectos sino de observar qué incentivos generan sus mecanismos.

\section{La democracia representativa o democracia electoral}

La democracia representativa electoral es el único de los modelos abordados que puede observarse empíricamente en perspectiva sistémica, esto es, que sus aspectos fundamentales - organización y distribución del poder- funcionan asociados al modelo, al menos en abstracto, en un número considerable de casos. Hay diferentes manifestaciones (sistemas presidencialistas vs sistemas parlamentarios, poder judicial electo o nombrado por los representantes, etc.) pero las elecciones ocupan el lugar central en la distribución del poder. Estos cuerpos electos tienen la obligación de legislar mientras los principales mecanismos de control radican en el sistema de pesos y contrapesos (horizontal, control ejercido entre poderes) y en las elecciones (vertical, que permite ratificar o no a representantes y/o partidos en los puestos de poder).

\footnotetext{
3 "Lo llaman democracia y no lo es" fue uno de los lemas principales del movimiento ciudadano originado en España en el 2011 conocido como Movimiento 15M o indignados. Por su parte, "Somos el 99\%" constituye uno de las consignas principales en denuncia de la concentración de riquezas en pocas manos que fue empleada por el movimiento Occupy y generalizado en septiembre del 2011. Ver Flesher Fominaya (2014).
} 
Unos procedimientos -las elecciones-, y unos requisitos -que sean libres, competitivas y justas-, permiten seleccionar a las personas encargadas de la toma de decisiones y distribuir el poder político. La arena política se define como un proceso competitivo en el que representantes de intereses plurales luchan por adquirir la confianza de la ciudadanía, que periódicamente los elige en procesos electorales. La elección (mediante el voto) es vista como la esencia de las democracias y como el método idóneo para seleccionar a «los mejores» (Schumpeter, 1984). Como contrapartida, la ciudadanía adquiere la posibilidad de fomentar un proceso de rotación de representantes mediante su voto. Es decir, son protagonistas en la medida que pueden penalizar a aquellos/ as representantes que han decepcionado como promocionar nuevas figuras. La elección se considera no sólo el método más eficaz sino también el instrumento democrático por antonomasia en sociedades complejas y ampliamente pobladas.

La democracia representativa obtiene mayor legitimidad y apoyo cuando logra consolidar altos índices de participación electoral y afiliación a partidos políticos y sindicatos. Un ejemplo emblemático de esta circunstancia se observó durante la transición española. El proceso se dio a través de acuerdos entre el régimen y los representantes de partidos políticos, sin participación ciudadana. Sin embargo, debido a que partidos y sindicatos contaban con legitimidad de la ciudadanía, no hubo mayor cuestionamiento a la escasa publicidad con que se dieron las negociaciones (Linz y Stepan, 1996; Soto y Welp 2017).

Las críticas al funcionamiento del sistema remiten a Aristóteles (la democracia como sistema desvirtuado pero también como forma de oligarquía: "que algunos deliberen sobre todas las cuestiones es propio de la oligarquía" Política, Libro IV, 1298a, 7 y a Michels (2008). Siguiendo a este último, los partidos políticos forman la nueva oligarquía, que establece filtros de acceso que limitan considerablemente la sola posibilidad de competir por cargos. Además, en sociedades de masas las campañas electorales tienen un gran peso en la definición de preferencias pero participar en las mismas requiere de dinero, lo que también establece filtros de entrada y condiciona fuertemente la capacidad de ser elegidos. Estos filtros se han visto reducidos con la expansión de medios digitales que, por un lado, permiten hacer campañas con menor coste y mayor llegada (al menos potencialmente) pero también han amplificado el alcance de discursos que apelan a las emociones más que a los argumentos. A la vez, el surgimiento reciente de nuevos partidos es una prueba de que incluso si la democracia representativa es menos abierta de lo que en teoría se supone, tampoco es un sistema cerrado. Aún así, el formato de los partidos continúa siendo dominante, mientras desde otras perspectivas se plantea la apertura no sólo de la representación (a nuevos actores) sino también de la definición de los asuntos públicos. Así, la debilidad del sistema se evidencia por la necesidad de hacer más eficientes sus mecanismos de selección, ejercicio y control del poder. 


\section{La democracia participativa o directa}

En las distintas gradaciones de implicación ciudadana que reclaman los modelos de democracia en competencia, las propuestas de democracia directa o participativa entienden que la ciudadanía debe poder decidir sobre aquellos aspectos que le afectan. Esta visión de la democracia engloba una variedad de propuestas -"radical democracy" de Pateman (1979), "strong democracy" de Barber (2004), "participatory democracy" de Avritzer y Santos (2004)-, que aún presentando matices relevantes entre sí comparten una decidida defensa de la necesidad de impulsar mecanismos de participación efectivos (y no meramente simbólicos) en la toma de decisiones. Son modelos que entienden que debe producirse una distribución de responsabilidades real en el ejercicio del poder político, de manera que no quede relegada a un grupo especial o selecto de representantes y que tampoco quede limitada al ejercicio de influencia desde la sociedad civil. A pesar de esto, la diversidad al interior de estas teorías es evidente, con propuestas radicales que buscan el reemplazo total de la democracia representativa (que no cuentan con antecedentes empíricos más allá de experiencias breves y controvertidas, como la Comuna de París ${ }^{4}$ ) hasta otras que ven con buenos ojos el despliegue de mecanismos de participación indirectos (como los concejos y conferencias de políticas públicas según el modelo desarrollado en Brasil). En definitiva, estamos ante una interpretación de la democracia que defiende una ampliación del significado ( $\mathrm{y}$ de las posibilidades) del concepto de participación (Baiocchi y Ganuza, 2016).

Los mecanismos destacados en este marco son los referendos y las iniciativas ciudadanas. Estos pueden ser activados por las autoridades ("desde arriba"), por recolección de firmas ("desde abajo") o por mandato constitucional ("obligatorios"), en situaciones específicas (Ríos y Cairo, 2018). Suiza es el caso emblemático en el ejercicio de estos mecanismos que fueron regulados en la primera Constitución de la Confederación en 1848. En este país, los mecanismos de democracia directa (MDD) fueron introducidos y ampliados como instrumentos de salvaguarda del poder (en sus orígenes, de los cantones frente al incipiente gobierno confederal) y posteriormente de la ciudadanía (con la introducción de mecanismos desde abajo) (Massüger y Welp 2014). Numerosos estudios dan cuenta de los efectos positivos de estos mecanismos de control tanto para la eficiencia del gobierno como para la legitimidad del sistema (Serdült, 2018). Pero incluso el sistema suizo, con sus centenares de votaciones anuales en todos los niveles de gobierno, no es considerado un sistema de democracia directa sino semi-representativo en el que la mayoría de las decisiones son tomadas por las instituciones representativas. El potencial

${ }^{4}$ La Comuna de Paris fue un periodo de gobierno auto-gestionado que se dio en la ciudad Parisina entre marzo y mayo de 1871 tras la caída del gobierno imperial de Napoleón III.

Araucaria. Revista Iberoamericana de Filosofia, Política, Humanidades y Relaciones Internacionales, año $21, \mathrm{n}^{\circ} 42$. Segundo semestre de 2019. Pp. 585-604. ISSN 1575-6823 e-ISSN 2340-2199 doi: 10.12795/araucaria.2019.i42.25 
de los MDD radica en ofrecer instrumentos directos y vinculantes de control (veto) y a ampliación de la agenda (iniciativas) (Welp, 2018).

Las críticas clásicas a la democracia directa refieren a la dificultad de integrar al conjunto de la ciudadanía en sociedades altamente pobladas y complejas, la protección de las minorías si las decisiones se toman exclusivamente por regla de mayoría; las desigualdades en aspectos sociales, culturales o económicas así como el posible desinterés de amplias partes de la población sobre aquello que tiene que ver con la política (Keane, 1984); a lo que se suma la potencial manipulación y usos plebiscitarios (Sartori, 1999). Las primeras críticas son contradichas por el caso suizo mientras la apelación al plebiscitarismo está asociada a diseños de mecanismos activados desde arriba. Esto se observa con cierta frecuencia en la experiencia latinoamericana, donde los referendos son activados para reforzar el poder de quienes ya concentran el poder más que para contrarrestarlo. Aún así, también puede mencionarse que cuando las reglas electorales funcionan estos pueden ver derrotadas sus mociones, como ha ocurrido en algunas ocasiones (Welp y Ruth, 2017). En definitiva, no se trataría aquí estrictamente de un modelo ya que los mecanismos propuestos apuntan a complementar la toma de decisiones incorporando la decisión ciudadana en ocasiones específicas. Esto altera el ejercicio del poder y añade mecanismos de control (por ejemplo con revocatorias de mandato o referendos abrogativos) pero no reemplaza otros mecanismos de rendición de cuentas (por ejemplo, el Poder judicial) ni tampoco la intermediación ejercida por las autoridades representativas. Su principal punto débil: el descuido de los procesos de formación de la opinión pública.

\section{Democracia deliberativa}

La democracia deliberativa entiende que los procesos de comunicación que se producen en el seno de la sociedad civil son el elemento clave para profundizar y mejorar el sistema político (García Marzá, 2016). Desde esta visión, la formación de opinión pública crítica y plural es indispensable para fomentar una democracia de calidad. De ahí que se considere la relevancia de reforzar los procesos de deliberación en la configuración de la agenda política así como de influir en la toma de decisiones (Habermas, 1998; Fishkin, 1997). Aquí se entiende que la participación debe definirse en términos comunicativos de manera que la ciudadanía emprenda procesos deliberativos racionales en torno a materias de interés público (Cortina, 1993 y 2010). Las concepciones deliberativas de la democracia insisten en la relevancia de contar con una opinión pública de calidad resultado de procesos inclusivos, plurales y no coactivos. Finalmente, reclama que los resultados de la deliberación sean tenidos en cuenta por los que ejercen de representantes, dado que éstos son a fin de cuentas los que toman la decisión final. 
El talón de Aquiles de la democracia deliberativa es su materialización, ya que sólo se ha dado en experiencias de menor rango, como las de los mini públicos, o en el ámbito de los movimientos sociales. Las primeras muestran las bondades de la deliberación para mejorar la formación de la opinión pública en base a argumentos, pero se han producido en muy pequeña escala y casi como experiencias de laboratorio (con muchas condiciones bajo control) (Setälä, 2017). Las que se han dado a gran escala y autogestionadas pertenecen, como decíamos, al ámbito de los movimientos sociales. Movimientos como el de los indignados tomaron forma a partir de la organización asamblearia, horizontal, ocupando espacios públicos, con la plaza como lugar de referencia. El 15M, el \#yosoy132 o Ocuppy Wall Street protestan mientras ponen en práctica la sociedad en la que les gustaría vivir (Della Porta, 2015; Flesher Fominaya, 2015). La deliberación funciona aquí, pero por fuera de los ámbitos de toma de decisiones y tiene enormes dificultades para sostenerse en el tiempo.

Además de las limitaciones empíricas observadas, la democracia deliberativa requiere de condiciones normativas en cuya ausencia las experiencias deliberativas se pervierten. El diseño del procedimiento deliberativo, ya sea fomentado exclusivamente desde la sociedad civil o sea promocionado desde instituciones del Estado, deberá satisfacer una serie de principios claves basados en la inclusión, pluralidad, no coacción, etc. (Habermas, 1998). De no respetarse dichos principios, la calidad de la opinión pública quedaría claramente perjudicada. A esto se agrega que el proceso no sólo debe ser justo, sino también ser percibido como tal para poder generar confianza. Por otro lado, este modelo de democracia exige que las autoridades políticas (o el centro político, empleando la terminología de Habermas) se mantengan porosas y abiertas a una escucha activa de las voces que provienen desde la sociedad civil (periferia, por mantener la misma terminología). De no cumplirse esta condición, los efectos prácticos de la deliberación pueden ser nulos en cuanto a su influencia sobre la toma de decisiones. Un uso desvirtuado vendría dado en los casos en los que representantes políticos organizasen procesos de deliberación a los que luego ignoran o usan simbólicamente. También los procesos espontáneos producidos desde la sociedad civil requieren que este principio de apertura se produzca de manera que la deliberación no quede en saco roto y produzca un proceso racionalizador de la toma de decisiones.

\section{La democracia por sorteo o representativa aleatoria}

El sorteo parece dar respuesta a algunas de las principales críticas recibidas por la deliberación. Los modelos de democracia representativa aleatoria consideran que la representación electoral es solo una posible variante de los 
sistemas basados en la representación. Empleado ya en la democracia ateniense clásica, el sorteo se postula como la alternativa ideal para abrir y ampliar a toda la ciudadanía la posibilidad de ser tanto gobernado como gobernante, considerándose el medio idóneo para ampliar los perfiles presentes en los órganos representativos (Manin, 1998; Sintomer, 2012 y 2017). Además, se cree que es un recurso capaz de fomentar la independencia y capacidad crítica de los representantes escogidos al azar (quienes no deberían su puesto a ninguna estructura política ni a ninguna futura reelección) (Moreno Pestaña, 2017; Feenstra, 2017). El objetivo se centra en reducir la distancia entre gobernantes y ciudadanía de manera que se fomente la inclusión y la confianza entre estos. Las elecciones basadas en la selección "de los mejores" se perciben como un mecanismo de los "pocos" en la que una mayoría no tiene posibilidades reales de ejercer el poder y donde se produce, en definitiva, la consolidación de una "aristocracia electiva" que conviene revisar con la incorporación de la aleatoriedad (van Reybrouck, 2016; Burnheim, 1985).

Esta interpretación de la democracia postula que una representación descriptiva (representantes semejantes a aquellos a quienes representan) mejora la representación sustantiva (la definición de políticas para todos). El repertorio político sigue basado en la intermediación mediante representantes, como en el modelo de democracia representativa electoral, pero ahora con la incorporación del sorteo como mecanismo de selección capaz de profundizar y mejorar la democracia. Las diferentes propuestas de democracia aleatoria varían en el nivel de aplicación del sorteo y van desde propuestas que abogan por una totalidad de representantes escogidos al azar, como defiende Burnheim en Demarchy (1985), hasta modelos bi-representativos que proponen la complementariedad entre elección y sorteo (van Reybrouck, 2016: 157).

La opción del sorteo se plantea no solamente como un posible modelo de democracia más - en propuestas como las de Burheim o van Reybrouck- sino también como una herramienta o complemento disponible para democratizar aunque sea parcialmente- tanto el sistema político (con diferentes experimentos o laboratorios democráticos como los mini-públicos, los jurados ciudadanos, comisiones legislativas ciudadanas, etc.) como instituciones representativas claves (partidos políticos, parlamentos, ayuntamientos, etc.). De hecho, en los últimos años se ha recurrido a este mecanismo en las asambleas ciudadanas constituidas en la Columbia Británica y en Ontario (Canadá), donde representantes electos al azar debatieron posibles reformas de la ley electoral, así como en el conocido G1000 de Bélgica de 2011 donde se buscaba reunir a mil ciudadanos escogidos por sorteo para deliberar en torno a cuestiones de interés público (van Reybrouck, 2016). No obstante, el caso actual más destacado es quizás el llevado a cabo por la Convención Constitucional Irlandesa, una iniciativa lanzada en 2013 desde el propio Parlamento con la finalidad de 
debatir la reforma de la Constitución en la que 66 personas (de un total de 99) fueron escogidas al azar con la finalidad de mejorar la Constitución en un procedimiento que aunaba tres mecanismos como son el sorteo, la deliberación y la posterior votación vinculante de toda la ciudadanía en referéndum (Farrell et al, 2017). La experiencia ha sido celebrada al punto de que se ha replicado posteriormente para la modificación de la ley regulatoria del aborto.

\section{Democracia como contra-poder o monitorizada}

Finalmente, han surgido propuestas que depositan la confianza en el aspecto comunicativo como forma de contra-poder, agrupadas bajo el concepto de democracia monitorizada. Desde estas visiones se defienden los efectos regeneradores que acompañan a la comunicación como espacio y herramienta de fiscalización y escrutinio público de los centros de poder político y económico. La ampliación del repertorio político con respecto al modelo estrictamente representativo se centra en la fiscalización y monitorización de los núcleos que poder. Así, pues, se reclama la presencia de ciudadanía como atenta observadora que actúa y denuncia públicamente en el momento que se producen arbitrariedades. La lucha a favor de la transparencia y en contra de la corrupción y los abusos de poder se erigen como los elementos claves para profundizar la democracia, fomentar la pluralidad y redistribuir (o equilibrar) las relaciones de poder (Rosanvallon, 2008; Keane, 2009). Se confía en la capacidad de la ciudadanía de presionar e influir activando diferentes contrapoderes y actuando como correctora del proceso político. Es decir, es un proceso que (por lo general) no viene impulsado desde las instituciones sino que surge desde la propia iniciativa de la sociedad civil que reacciona y muestra su capacidad de acción ante los abusos de poder o arbitrariedades (Schudson, 1998; Feenstra, 2013; Calvo, 2018).

Los ejemplos de democracia monitorizada provienen tanto del ámbito formal como del informal o no gubernamental. Destaca la plataforma WikiLeaks, con sus denuncias, entre otros, de los métodos contrarios a los derechos humanos que fueron empleados en las guerras de Afganistán e Irak. O el "Caso Snowden" donde el extécnico de la CIA, Edward Snowden, reveló al mundo el uso masivo de sistemas de vigilancia y espionaje aplicados a millones de personas de todo el mundo. En el contexto político español también existen experiencias destacados de monitorización como la plataforma 15MpaRato donde un grupo de activistas destapó la irregular salida a bolsa de Bankia (Feenstra y Keane, 2014).

Como puede deducirse de la descripción, este no es un modelo de gobierno en tanto no establece procesos de selección de autoridades ni de toma de decisiones, sino que se centra en controlar procedimientos 
establecidos añadiendo un mecanismo capaz de supervisión sin buscar reemplazar las instituciones existentes. Aún así, igualmente enfrenta retos institucionales (así como malas interpretaciones de lo que exige desde el punto de vista normativo) que, de no ser resueltos, pueden derivar en una versión desvirtuada de la misma. La monitorización como proceso político deseable implica un acto de escrutinio público de un asunto de interés público y, además, exige que se justifique mediante la aportación de pruebas o evidencias del abuso de poder cometido. Es decir, un proceso basado en la mera crítica o linchamiento público e infundado hacia un representante constituiría una corrupción del ideal democrático que aquí se exige. También es contrario a este modelo de democracia la defensa de la vigilancia masiva de la ciudadanía en un proceso de arriba abajo orientado a reforzar los centros de poder, ya que ello implica lo contrario del principio democrático que este modelo postula y que se basa en la defensa por la descentralización del poder y el desarrollo de contrapoderes.

\section{Discusión y conclusiones}

En la tabla que incluimos a continuación se sintetizan los principales elementos de los modelos presentados en la sección anterior. Proponemos que en lugar de funcionar como alternativa a la democracia representativa, lo que hacen es proponer mecanismos complementarios a los representativos por eso sugerimos hablar de ecología de la participación-. En pocas palabras, no estaríamos ante modelos en disputa sino ante una serie de mecanismos que bien diseñados podrían dar respuestas a la crisis actual de la democracia representativa: 


\begin{tabular}{|c|c|c|c|c|c|}
\hline $\begin{array}{l}\text { Modelo de } \\
\text { democracia }\end{array}$ & $\begin{array}{l}\text { Representativa } \\
\text { electoral }\end{array}$ & Directa & Deliberativa & Aleatoria & Monitorizada \\
\hline $\begin{array}{l}\text { Mecanismo } \\
\text { principal }\end{array}$ & Voto & $\begin{array}{l}\text { Participación } \\
\text { directa }\end{array}$ & Deliberación & Sorteo & $\begin{array}{l}\text { Monitorización/fi } \\
\text { scalización }\end{array}$ \\
\hline $\begin{array}{l}\text { Principio } \\
\text { básico }\end{array}$ & $\begin{array}{l}\text { Competencia } \\
\text { electoral }\end{array}$ & $\begin{array}{l}\text { Co- } \\
\text { responsabilidad }\end{array}$ & Consenso & Rotación & Transparencia \\
\hline $\begin{array}{l}\text { Función } \\
\text { principal } \\
\text { del proceso } \\
\text { político }\end{array}$ & Legitimar & Decidir & Racionalizar & Legitimar & Racionalizar \\
\hline $\begin{array}{l}\text { Sistema de } \\
\text { control }\end{array}$ & $\begin{array}{l}\text { Castigo o } \\
\text { reconocimiento de } \\
\text { la labor de los } \\
\text { gobernantes } \\
\text { mediante el voto }\end{array}$ & $\begin{array}{l}\text { Compartición } \\
\text { de } \\
\text { responsabilidad } \\
\text { en la toma de } \\
\text { decisiones entre } \\
\text { gobernantes y } \\
\text { gobernados }\end{array}$ & $\begin{array}{l}\text { Presión desde la } \\
\text { sociedad civil } \\
\text { mediante el } \\
\text { diálogo y la } \\
\text { crítica. }\end{array}$ & & $\begin{array}{l}\text { Presión desde la } \\
\text { sociedad civil } \\
\text { mediante la } \\
\text { denuncia de los } \\
\text { abusos de poder }\end{array}$ \\
\hline Ejemplo & $\begin{array}{l}\text { Funcionamiento } \\
\text { sistémico. Ej. } \\
\text { España, } \\
\text { democracias } \\
\text { europeas y } \\
\text { latinoamericanas }\end{array}$ & $\begin{array}{l}\text { Funcionamiento } \\
\text { a nivel de } \\
\text { mecanismos (no } \\
\text { sistémico) Ej. } \\
\text { Suiza }\end{array}$ & $\begin{array}{l}\text { Funcionamiento } \\
\text { a nivel de } \\
\text { mecanismos (no } \\
\text { sistémico) Ej. } \\
\text { minipúblicos }\end{array}$ & $\begin{array}{l}\text { Funcionamiento } \\
\text { a nivel de } \\
\text { mecanismos (no } \\
\text { sistémico) Ej. } \\
\text { Asambleas y } \\
\text { jurados en } \\
\text { Australia, } \\
\text { Irlanda, etc. }\end{array}$ & $\begin{array}{l}\text { Funcionamiento a } \\
\text { nivel de } \\
\text { mecanismos (no } \\
\text { sistémico) Ej. } \\
\text { Plataformas de } \\
\text { filtración de } \\
\text { información. }\end{array}$ \\
\hline
\end{tabular}

Observamos que cada propuesta tiene una comprensión diversa respecto al poder (cratos) que puede o debe ejercer la ciudadanía (demos). Además, cada propuesta atribuye un papel diferente a la ciudadanía como actor político. Las sociedades se han vuelto más complejas, los medios digitales han generado nuevas formas de producción y puesta en circulación de la información mientras la confluencia de esto con otros procesos (la globalización, las dinámicas capitalistas) ha cambiado considerablemente la estructura de incentivos y retos que la arena política enfrenta. Por ello, sostenemos, la democracia representativa requiere de ser transformada. Su transformación no pasa por su reemplazo -como hemos intentado mostrar, las alternativas existentes no permiten suponer que sea viable- sino por un cambio relevante que permita integrar a la ciudadanía en diferentes formas mediante una ecología de la participación (en esta línea véase Zaremberg y Welp, 2019)

Los problemas de la democracia representativa han sido ampliamente analizados y afectan a: 1) la limitada capacidad de influencia que el sistema permite a la ciudadanía más allá de las elecciones representantes; 2) la erosión de la esfera pública como espacio de formación cívica y de intercambio racional sobre los asuntos públicos; 3 ) la distancia creciente entre la "oligarquía" y la ciudadanía, que erosiona la democracia y alimenta el discurso populista; y 4) la escasa capacidad de controlar el poder. La demagogia encuentra aquí incentivos 
específicos, debido a que las dinámicas electorales promueven campañas centradas en estrategias de marketing basadas en encuestas (que permiten a los candidatos identificar y adaptar a sus discursos lo que creen que la gente espera escuchar).

Frente a la limitada capacidad de influencia que el sistema representativo más estricto permite a la ciudadanía, la democracia participativa propone incluirla en la toma de decisiones. No se trata de legitimar el proceso (sólo) mediante el voto (modelo representativo), de mejorar la pluralidad representativa mediante la aleatoriedad (modelo basada en el sorteo) o de impulsar determinados procesos de comunicación en el seno de la sociedad civil (modelos deliberativos o monitorizados) sino de participar de forma directa en la toma de decisiones colectivas. Una condición básica que aquí se plantea -y que también afecta a algunos otros mecanismos de toma de decisioneses que su implementación y consolidación depende de que las instituciones acepten e incorporen los mecanismos de democracia directa. De no ser así sólo se fomentarán procesos de participación espontáneos e informales, de abajo arriba, sin una institucionalización de la participación directa. Además, la llamada a la participación requiere que se garantice la posibilidad de tomar (y debatir) posturas, conocer las ventajas e inconvenientes de los procesos por los que se vota y formarse un criterio propio a la hora de decidir. El uso del referéndum como simple aprobación de decisiones ya tomadas de antemano promociona el plebiscitarismo. Los mecanismos activados por las autoridades serían, en este sentido, los más susceptibles a la demagogia en la medida en que los líderes políticos podrían recurrir a ellos para movilizar a las bases más que para realmente incluir a la ciudadanía a la toma de decisiones. Europa es un laboratorio de prácticas de este tipo, con consultas como las promovidas por Viktor Orban en Hungría para rechazar la inmigración y la acogida de refugiados. Los mecanismos activados desde abajo serían menos susceptibles a esta manipulación y utilización demagógica pero tampoco quedan exentos, como muestra la consulta promovida en Holanda en 2016, contra el tratado de libre comercio con Ucrania, promovida también por el líder de la derecha xenófoba Geert Wilders (Partij voor de vrijheid PVV - Partido por la libertad). Estos riesgos podrían ser limitados por la mejora de las condiciones de formación de la opinión pública, en la línea de la propuesta de las teorías de la deliberación.

La segunda problemática, que afecta a la erosión de la esfera pública como espacio de formación de la ciudadanía y de intercambio racional sobre los asuntos públicos, puede ser resuelta (en una medida realista, nunca clausurando el problema) por la deliberación. La deliberación además de ser un procedimiento clave en la "ecología de la participación" se constituye como un proceso capaz de promocionar argumentos y un debate informado 
para la toma de decisiones. La deliberación se piensa como un instrumento de mejora, así como de cohesión social entre la sociedad civil y la clase política, pero necesita garantizar la representatividad de las personas que participan así como establecer con claridad las consecuencias de las decisiones tomadas. El gran reto de la deliberación como mecanismo per se de organización del poder deriva de su falta de legitimidad en caso de no combinarse con mecanismos de selección que permitan alguna forma de representación.

La tercera de las problemáticas señaladas y que afecta a la creciente distancia entre representantes y ciudadanía puede ser resuelta o al menos disminuida mediante el recurso al sorteo, al menos en algunas instituciones. El sorteo surge como mecanismo ideal, superando las limitaciones de una deliberación de pequeña escala. Además, como ya hemos señalado, el sorteo es un mecanismo esencial en la complementación con otros sistemas como la deliberación pública sobre medidas a emprender o la votación en referéndum vinculante del conjunto de la ciudadanía. Para que este sistema funcione es relevante asegurar el correcto muestreo de cara a lograr la representación descriptiva. Por su parte, tiene como reto y dificultad (del mismo modo que sucede con los MDD) el definir quién garantiza la implementación así como el desarrollo del proceso. El sorteo implica una apertura de las instituciones a representantes electos por vías alternativas a la electoral y precisa que estos representantes (los escogidos por vía electoral) aprueben o incorporen el sorteo como sistema al menos complementario.

Finalmente, la escasa capacidad de controlar el poder que se achaca a las democracias representativas tiene en la monitorización un potencial complemento desde la cual afrontarla. La monitorización puede constituirse como un eficaz remedio para la lucha contra la opacidad y los abusos de poder. El desarrollo constante de un amplio abanico de medios de comunicación digitales facilita la extensión de este tipo de procesos. Sin embargo, su buen funcionamiento también se basa en una serie de condiciones claves. Por ejemplo, el acceso a la información y la separación de poderes. Lo primero es indispensable para el ejercicio de la monitorización y lo segundo una condición fundamental ya que, si las denuncias no se juzgan posteriormente en los canales adecuados, se puede generar un incremento de frustración en la ciudadanía ante la constatación de que los contra-poderes tienen una influencia sólo parcial, de denuncia. La existencia de una amplia pluralidad de medios de comunicación que reflejen los casos de monitorización o de representantes políticos que asuman las responsabilidades políticas cuando son públicamente expuestos también son condiciones relevantes. Aún basado en las condiciones mencionadas, la monitorización depende fundamentalmente del accionar de la sociedad civil, mientras el resto de mecanismos del marco regulatorio. Por esto, su desarrollo efectivo depende primero de la voluntad política de implementar 
cambios institucionales que en buena medida pueden orientarse a limitar el poder de quienes los activan, mientras para hacerse efectivos dependen del cumplimiento de la normativa.

En definitiva, argumentamos que los partidos, organizaciones y/o movimientos políticos tienen una función relevante organizando preferencias, generando temas, impulsando una agenda programática para la organización de la res pública. Para que esto se haga efectivo, es necesario que se cumplan condiciones internas, de democratización de los partidos y externas, de mejora de las condiciones de formación de la opinión pública y fortalecimiento de los instrumentos de control. Los mecanismos de democracia directa, combinados con procesos deliberativos, monitorización y la implementación del sorteo pueden contribuir. Es clave el acceso a la información. Pero todo eso no basta. Cabe entonces considerar otras condiciones complementarias. Ya Aristóteles señalaba que:

cuando la ciudad está constituida sobre la igualdad y semejanza de los ciudadanos, se considera justo que estos ejerzan la autoridad por turno. En una época anterior, juzgaban digno cumplir un servicio público turnándose, como es natural, y que otro, a su vez, velara por su interés, como antes él, cuando gobernaba, miraba por el interés de aquél. Mas ahora, a causa de las ventajas que se obtienen de los cargos públicos y del poder, los hombres quieren mandar continuamente, como si el poder procurase siempre la salud a los gobernantes en estado enfermizo. En esas circunstancias, sin duda perseguirán los cargos (Política, Libro III, 1279a, 9).

La democracia se fortalece no sólo con mejores procedimientos de distribución del poder sino también con mejores condiciones de vida para la ciudadanía. A esto se agrega la importancia de la regulación. El sorteo y los mecanismos de democracia directa, como también los procesos electorales convencionales, descansan buena parte de su funcionamiento sobre procedimientos bien diseñados y adecuadamente supervisados. 


\section{Referencias:}

Alonso, S. Keane, J. y Merkel, W. (eds.) (2011). The Future of Representative Democracy. Cambridge: Cambridge University Press, 2011.

Aristóteles, (1988). La política. Madrid: Gredos

Baiocchi, G., y Ganuza, E. (2016). Popular democracy: The paradox of participation. Stanford University Press.

Barber, B. (2004). Democracia fuerte: politica participativa para una nueva época. Córdoba: Almuzara.

Burnheim, J. (2006). Is Democracy Possible?: The Alternative to Electoral Democracy, Sidney, Sydney University Press.

Calvo, P. (2018). The Cordial Economy - Ethics, Recognition and Reciprocity, Cham, Springer.

Cortina, A. (1993). Ética aplicada y democracia radical, Madrid, Tecnos.

Cortina, A. (2010). Las raíces de la democracia, València, Universitat de València.

Dahlberg, L. y Siapera, E. (eds.) (2011). Radical democracy and the Internet: Interrogating theory and practice. Springer.

Della Porta, D. (2015). Social Movements in Times of Austerity. Polity Press.

Dryzek J. S. (2002). Deliberative Democracy and Beyond: Liberals, Critics, Contestations. Oxford: Oxford University Press.

Eberhardt, M. L. (2015). "Democracias representativas en crisis. Democracia participativa y mecanismos de participación ciudadana como opción". Araucaria, 17(33), 86-103.

Farrell, D. Harris, C. y Suiter, Jane (2017). "Bringing People into the heart of constitutional design". En X. Contiades y A. Fotiadou. Participatory Constitutional Change: The People as Amenders of the Constitution. Londres: Routledge.

Feenstra, R. A. (2013). "Una reflexión sobre la Democracia Monitorizada: potencialidades y límites”. Foro Interno. Anuario de Teoría Política, 13, $139-160$.

Feenstra, R. A. (2017). "Democracia por sorteo en las nuevas formaciones políticas: Un debate con rastros de la teoría política clásica y contemporánea”. Daimon Revista Internacional de Filosofía, 72, 205-219.

Feenstra, R. A., y Keane, J. (2014). "Politics in Spain: A case of monitory democracy". Voluntas: International Journal of Voluntary and Nonprofit Organizations, 25(5), 1262-1280.

Fishkin, J. S. (1997). The voice of the people: Public opinion and democracy, New Haven: Yale University Press. 
Flesher Fominaya, C. (2014). Social Movements and Globalizations. How Protest, Occupations and Uprising are Changing the World. Nueva York: Palgrave

García-Marzá, D. (2016). "Enfoques mesodeliberativos: sobre la articulación institucional en las democracias deliberativas". Isegoría, 54, 147-170.

Giddens, A. (2013). Politics and sociology in the thought of Max Weber. Nueva York: John Wiley \& Sons.

Habermas, J. (1998). Facticidad y validez. Madrid: Trotta.

Held, D. (1991). Modelos de democracia. Madrid: Alianza.

Keane, J. (2003). Global civil society? Cambridge: Cambridge University Press.

Keane, J. (2009). The Life and Death of Democracy, Londres y Nueva York: Simon \& Schuster.

Keane, J. (1984). Public life and late capitalism: essays toward a socialist theory of democracy. Cambridge: Cambridge University Press.

Linz, J. y Stepan, A. (1996). Problems of democratic transition and consolidation. Baltimore: Johns Hopkins University Press.

Mair, P. (2015). Gobernando el vacio: la banalización de la democracia occidental. Madrid: Alianza Editorial.

Manin, B. (1998). Los principios del gobierno representativo. Madrid: Alianza.

Massüger, Nina y Welp, Y. (2014). "La democracia directa y sus diferentes culturas. Análisis de las experiencias suiza, europea y latinoamericana", 337-370. En Báez Silva y Ríos Vega (Coords.) Los derechos políticos en el siglo XXI. México: Tirant O Blanch.

Michels, R. (2008). Los partidos politicos II. Un estudio sociológico de las tendencias oligárquicas de la democracia moderna. Buenos Aires: Amorrortu.

Moreno Pestaña, J. L. (2017). "Los desafíos del sorteo a la democracia, los desafíos de la democracia al sorteo". Daimon Revista Internacional de Filosofía 72, 7-21.

Pateman, C. (1979). Participation and Democratic Theory. Cambridge: Cambridge University Press.

Ríos, J., y Cairo, H. (2018). "Los discursos sobre la participación política en el proceso de paz de Colombia". Araucaria, (39), 317-339.

Rosanvallon, P. (2008). Counter-democracy: Politics in an age of distrust. Cambridge: Cambridge University Press.

Santos, Boaventura de Sousa y Avrtizer L. (2004). "Introducción: para ampliar el canon democrático", 35-74. En Santos B. (ed.). Democratizar la democracia. México: Fondo de Cultura Económica

Sartori, G. (1999). "En defensa de la representación política”. Claves de Razón Práctica, 91, 2-6. 
Schudson, M. (1998). The good citizen. A history of the American civic life. Nueva York: Martin Kessler Books.

Schumpeter, J. A. (1984). Capitalismo, Socialismo y Democracia. Barcelona: Folio.

Serdült, Uwe (2018). "Switzerland". En Qvortrup, M. (ed.). Referendums Around the World. Basingstoke: Springer, 47-112.

Setälä, M. (2017), "Connecting deliberative mini publics to representative decision making”. European Journal of Political Research, 56: 846-863. doi:10.1111/1475-6765.12207

Sintomer, Y. (2012): "Selección aleatoria, autogobierno republicano y democracia deliberativa". Enrahonar: quaderns de filosofia, 48, 133-156.

Sintomer, Y. (2017). "Sortition and Politics: From Radical to Deliberative Democracy?". Daimon-Revista Internacional de Filosofia, 72, 25-43.

Soto, F. \& Welp, Y. (2017) Los 'diálogos ciudadanos'. Chile ante el giro deliberativo. Santiago de Chile: LOM.

Tormey, S. (2015). The end of Representative Politics. Cambridge: Polity.

Van Reybrouck, D. (2016). Against elections: the case for democracy. Londres: Random House.

Verba, S. y Nie, N. (1972). Participation in America: Political democracy and social equality. Nueva York: Harper and Row.

Weber, M. (1978). Economy and society: An outline of interpretive sociology. Berkeley: University of California Press.

Welp, Y. y Saskia P. R. (2017) "The Motivations Behind the Use of Direct Democracy", in Ruth, Saskia P.; Welp, Yanina and Laurence Whitehead (Eds.) Let the People Rule? Direct Democracy in the Twenty-First Century. Colchester: ECPR Press, 99-119

Welp, Y. (2018). Todo lo que necesitás saber sobre las democracias del siglo XXI. Buenos Aires/Barcelona/Ciudad de México: Paidós.

Welp, Y., y Ordóñez, V. (2017). "La democracia directa a debate: procesos y mecanismos de participación ciudadana". Recerca. Revista de Pensament i Anàlisi, 21, 9-14.

Whitehead, L. (2011). "Un concepto de democratización reanimado: la metáfora biológica”. Revista SAAP, 5, 2, 401-419.

Zaremberg, G. y Welp, Y. (2019). "Beyond Utopian and Dystopian approaches to democratic innovation". Recerca. Revista de Pensament i Anàlisi, 24, pre-print, 1-16. 